\title{
Stanford's hope for heavy boson
}

Linear machine may give an edge on CERN

\section{Washington}

Physicists at the Stanford Linear Accelerator Center are keeping their fingers crossed during the next few weeks while the Office of Management and Budget (OMB) decides on their $\$ 44$ million request to begin construction of the Stanford Linear Collider (SLC) in fiscal year 1984. Approval would put SLC in the running with CERN's large electronpositron storage ring (LEP) to be the first machine to produce the roughly $90 \mathrm{GeV}$ electron-positron collisions needed to generate the elusive $\mathrm{Z}^{\circ}$ particle.

"If we get that funding," says Burton Richter, director of the SLC project, "we would be ready to turn on in October 1986 ". The $\$ 44$ million would be the first instalment of a total of $\$ 110$ million required for construction on a three-year schedule. LEP is scheduled for completion in late 1987.

Richter admits that the possibility of beating CERN to the punch has helped fuel enthusiasm for SLC. That enthusiasm seems to carry through the physics community and the Department of Energy's high-energy physics office, a broad base of support that may help the proposal over the twin hurdles of OMB and Congress. OMB's decision will not be made until December, and will not be made public until the President's 1984 budget is released at the end of January. At present, though, indications are that SLC may get the go-ahead. Earlier this year, the Energy Department's High Energy Physics Advisory Panel (HEPAP) strongly endorsed the project, recommending a 1984 start.

William Wallenmeyer, who directs the Energy Department's high-energy physics programme, points out that SLC has already rated "rather high priority"; the 1983 budget provides about $\$ 10$ million for research and development in connection with the project.

But in its closed-door deliberations, OMB may find several reasons to delay construction. Chief among them is that the physics aspect of SLC - namely the ability to study the $\mathrm{Z}^{\circ}$ - is only a part of the rationale behind the project. Wallenmeyer says the "primary justification" is that SLC would allow a new concept in accelerator design, called the "colliding linac", to be tested. This new breed may prove to be a less expensive alternative to the circular accelerators.

Thus a modest delay in SLC would not harm this primary goal. SLC would be built by adding a loop at the end of Stanford's existing linear electron accelerator. Electrons and positrons would be accelerated down the linear stretch; the electrons would then follow one branch of the loop, positrons the other, and they would collide at the far side of the loop. Energies of up to $50 \mathrm{GeV}$ per beam (100 $\mathrm{GeV}$ in the centre of mass in the collision) are anticipated.

Another possible counter to Stanford's push for a 1984 start and a quick three-year construction schedule is that the physics that can actually be done on SLC may in fact be rather limited. George Trilling of Lawrence Berkeley Laboratory chaired a HEPAP subpanel that last January recommended that SLC go ahead in 1984 even under a "low-budget" option - with the savings to come from a cut-back in Brookhaven's ISABELLE accelerator project; yet Trilling says that SLC is "not anywhere on the scale of LEP or ISABELLE; it's of a more limited scope". LEP, he says, will be of general use to highenergy physicists, while the physics on SLC will be limited to the $Z^{\circ}$ work. And Wallenmeyer points out that the actual discovery of the $\mathrm{Z}^{\circ}$ is likely to come from an existing machine at CERN, which collides proton and antiproton beams. "The purpose of LEP or SLC would be to pursue the resultant physics that comes out of that", Wallenmeyer says. The electron-positron

\section{CERN unafraid of Stanford}

Undismayed by the news from Stanford (see accompanying story), the European centre for nuclear research (CERN) is still hoping that it will find the heavy boson in the next few months.

Over the past 4 weeks, CERN's system for colliding protons and antiprotons with each other has been working much better than before. "We are now really in business", said CERN director Professor Herwig Schopper last week. The collisions should produce both the charged intermediate vector bosons, the $\mathrm{W}^{+}$and $\mathrm{W}$, and the neutral one, the $\mathrm{Z}^{\prime \prime}$. The collider is working well enough to produce "a few" bosons before Christmas, although it will be difficult to distinguish them from the many other particles produced in the high-energy collisions. The interest in the particles is that their existence is a clear prediction of presently widely accepted unified field theories, so that their detection will provide a critical test of the theories.

Meanwhile, contracts are now being prepared for around a third of the components for the construction of the large electron-positron collider, LEP, which is CERN's next major project. LEP is collisions in these machines make the interpretation of decay products much simpler.

None of this, however, discourages Richter in his role as director and chief proponent of SLC. Although SLC will have a single detector as opposed to LEP's four, he says, "SLC has as much physics potential as LEP."' Furthermore, he says, SLC will provide a smaller beam $(1.4 \mu \mathrm{m}$ radius compared with LEP's $500 \times 50 \mu \mathrm{m}$ cross-section), making the decay of shortlived particles easier to study; SLC will also be able to generate longitudinallypolarized beams, a boon in attaining high precision in weak-interaction experiments.

Richter also discounts the significance of LEP's higher energy capability. In its current design configuration, LEP will produce energies up to $80 \mathrm{GeV}$ per beam; going beyond that, Richter says, would require a new technology as yet untested. Richter says that once the $\mathrm{Z}^{\circ}$ resonance is reached at what is predicted to be $94 \mathrm{GeV}$ (47 GeV per beam), there is no interesting physics until about $200 \mathrm{GeV}(100 \mathrm{GeV}$ per beam), when pairs of charged $\mathrm{W}^{+} / \mathrm{W}^{-}$particles would begin to be produced in significant quantity.

For all of the build-up, the race between LEP and SLC may be determined in the starting gate if $\mathrm{OMB}$ decides to postpone construction of SLC. But if SLC gets the go-ahead for a 1984 start and a three-year construction schedule, it may be a race down to the wire. Stephen Budiansky

designed to give the clearest possible investigation of intermediate boson and related physics. The first contracts to be agreed have been for a major section of the $27-\mathrm{km}$ tunnel, for the production of 3.6 million magnet laminations and for steel and concrete cores for the magnets. They have gone to the lowest bidders, which have been consortia involving Italian, French, German, Swiss and Austrian companies. The prices have been roughly as planned, and certainly not low enough, says Schopper, to bring forward the completion date of late 1989.

Construction will not, however, begin until the French authorities give their environmental seal of approval. Twothirds of LEP lies in France, and one affected village, Echevenex, has made a particularly strong protest (see Nature 30 September, p.385). The local review procedure is now over, and CERN must now make its own representations to the committee. CERN has two possible new LEP designs for the Echevenex region. The committee will submit its recommendation to the French government which is expected to come to a decision early next year.
Robert Walgate 